
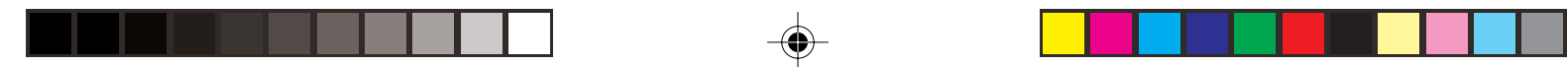

\title{
Manaus: um fotógrafo como turista aprendiz
}

Fernando de Tacca*

Escrever sobre minhas impressões ao fotografar Manaus depois de seis meses implica em perda inevitável do impacto imediato da chegada, andanças e o retorno, e me permito fazer essas considerações a partir do próprio roteiro fotográfico, ou seja, de como se configuraram fotograficamente essas impressões. Voltar a Manaus depois de quase 30 anos não foi algo muito diferenciado. A cidade que tinha em memória era de casarios e de uma cidade envolta em valores dos povos das águas. Minhas impressões de muitos anos atrás ainda estavam presentes na nova visita e penso que a cultura amazônica produzida nas águas ajudou a preservar a primeira imagem quando desci o rio Amazonas de barco até Belém em meio a redes e pessoas amáveis.

Ao editar as imagens do presente ensaio naturalmente o roteiro se estabeleceu sem muitas dúvidas. Preferi ficar no centro de Manaus na minha viagem em dezembro de 2006 para participar da primeira edição da Mostra Amazônica do Filme Etnográfico. A opção de estar em meio a uma grande cidade foi para sentir o ritmo urbano de seus habitantes e seu fluxo diário. Pouco tempo para fotografar a diversidade e a riqueza cultural de Manaus é uma angústia para qualquer fotógrafo, e principalmente por não podermos optar pela melhor luz, voltar ao lugar em outra hora. Por isso optei em ser um turista quase aprendiz com olhar de fotógrafo em busca de significações culturais, atrás de uma narrativa que tivesse um elo sintagmático dentro da sociabilidade manauara. Eu havia lido pouco antes dois romances de Milton Hatoum e estava envolvido por um clima afetivo e familiar com a cidade, principalmente pela minha origem também árabe.

Como toda cidade hoje no Brasil, a sonoridade invade nossos ouvidos com todos os tipos de sons e somos tomados pelo frenesi das idas e vindas. Entretanto, as pessoas não estavam em um ritmo tão infernal das grandes cidades, permitia-se parar, tomar um sorvete, sentar na praça, enfim, o ritmo era marcado por interrupções, nada contínuo em somente processo de passagem. Em meio a prédios e ônibus, a velha senhora espera o freguês para comprar um guarda-chuva, e homens sentam tranquilamente na sombra de grandes árvores. Pela noite, no entorno

*Fotógrafo, Antropólogo e professor livre docente no Departamento de Multimeios, Mídia e Comunicação, IA/Unicamp. E-mail: tacca@unicamp.br 
do teatro, nos sentimos em uma pequena cidade do interior, com famílias passeando, pipoca e tacacá.

Andar pelo centro, pelas grandes avenidas, rumo ao mercado, inevitavelmente nos leva às margens do Rio Negro e nesse momento tudo muda, outra cidade se descortina quando vemos o rio caudaloso e seus portos. Chega-se a um ponto de fronteira entre terra e rio. Aqui um ritmo de pessoas ansiosas para voltar para suas casas, ou chegando, se confunde com os trabalhadores que carregam todo tipo de mercadorias para os grandes barcos.

Viagens que se anunciam são de muitos dias e o tempo começa a entrar na dimensão das águas amazônicas. As redes são instaladas para o grande travelling de um cinema sem bordas em plano-seqüência sem fim. As pessoas disputam o exíguo espaço das tábuas que levam para o embarcadouro depois de caminhar um grande trecho do rio em época de seca. Existe um intervalo nessa época entre as embarcações e a grande murada da cidade, e nessa larga margem os caminhões adentram em meio às pessoas, tudo parece tornar-se uma coisa só.

Acompanhei um grupo de trabalhadores que portavam uma indumentária para proteger seu corpo e cabeça, fotografei-os de muitos ângulos. Carregavam sacos de farinha e suas capas eram um desses sacos de plásticos branco que carregavam. Vendo-os pelas costas eram super-heróis de capas brancas. Os flocos brancos os tornavam umbilicalmente ligados ao esforço do trabalho, uma relação de intrinsecalidade inevitável. Optei por trazer somente um retrato direto, não uma foto feita sem consentimento pelas costas, por mais que tenha procurado essa imagem. Os restos de farinha branca pelo rosto desse retrato são os detalhes da permanência e da impregnação do trabalho, como os rostos marcados pelo tom negro do carvão em fotos dos mineiros na obra de Lewis Hine. Houve uma generosidade do posar para o retrato, um estado de dupla autoria, sem a qual essa foto não existiria.

Fotografar em meio a essa situação incorre em perceber pelo aparelho detalhes que somente fotógrafos não deixam de notar. Por um lado, havia um estado de espera e de descanso, um intervalo para os navegantes prepararem um espírito das águas, mas, por outro lado, os trabalhadores de terra suavam ao percorrer o dique entre os navios. $\mathrm{Na}$ espera da viagem, o jovem marinheiro envolve-se na tecnologia recentemente apropriada pelo pequeno aparelho celular, talvez jogando, talvez enviando uma mensagem.

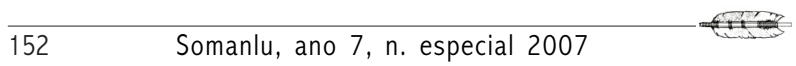


Surpreendente para um fotógrafo - um quase turista aprendiz na acepção de Mário de Andrade - é atravessar para a outra margem do rio Amazonas, passar pelo encontro das águas, e chegar a Careiro da Várzea, uma pequena comunidade amazônica, talvez possamos considerá-la como parte integrante da grande Manaus. Ali se experimenta andar por caminhos em cima do leito seco do rio. As ruas tornaramse extensas passarelas suspensas e toda a vila é entrecruzada pelos caminhos a dois metros de altura, ou mais. Temos dois planos de visão: no patamar das passarelas, acima do leito do rio, e para baixo onde a vida segue na terra como quintal das casas.

Ao andarmos pelos caminhos de madeira podemos participar da vida íntima das pessoas, dos banhos das crianças, e as janelas e portas se abrem para o olhar do passante, tudo se torna participante, mesmo para um visitante com câmera na mão. Essa situação é um convite ao fotógrafo pelo estado de estranheza favorável ao novo. A foto de uma criança tomando banho ao ar livre, aos fundos de sua casa, é um compartilhamento dessa intimidade não protegida aos olhos passantes. Sua pele mistura-se nas tonalidades da madeira que a rodeia e também aqui temos uma relação intrínseca da vivência desse povo. Na fotografia das pessoas sentadas e deitadas nas tábuas o corpo interage diretamente com o material, pele e madeira.

O fotógrafo tem vários pontos de vista oferecidos pela situação de proximidade do dia-a-dia. A cidade suspensa de madeira, com seus tons de cinza, um estado de temporalidade diferente da grande cidade não distante, e o transe fotográfico é inevitável, ou seja, somos absorvidos pelo campo do olhar fotográfico, pela descoberta do detalhe significativo de algum elemento da cultura.

Junto das casas estão a pequena venda, a igreja evangélica, a associação dos moradores, e a madeira que range o tempo todo. O som do ranger faz parte da percepção dessas pessoas. Talvez os passos e esse som da madeira sejam identificadores dos madrugadores. Seria preciso dormir uma noite para ouvir o cantar da madeira.

Eu e minha câmera nos tornarmos cúmplices de um olhar sobre Manaus e hoje ao percorrer minhas imagens digitais, as sensações visuais me levaram para alguns dos pontos de vistas que elegi nesse ensaio: o caminho natural do encontro da urbanidade asfáltica dos ônibus e prédios e certa urbanidade suspensa no ar pela cidade de madeira, uma edição entremeada pelas águas dos dois grandes rios formadores de Manaus. 

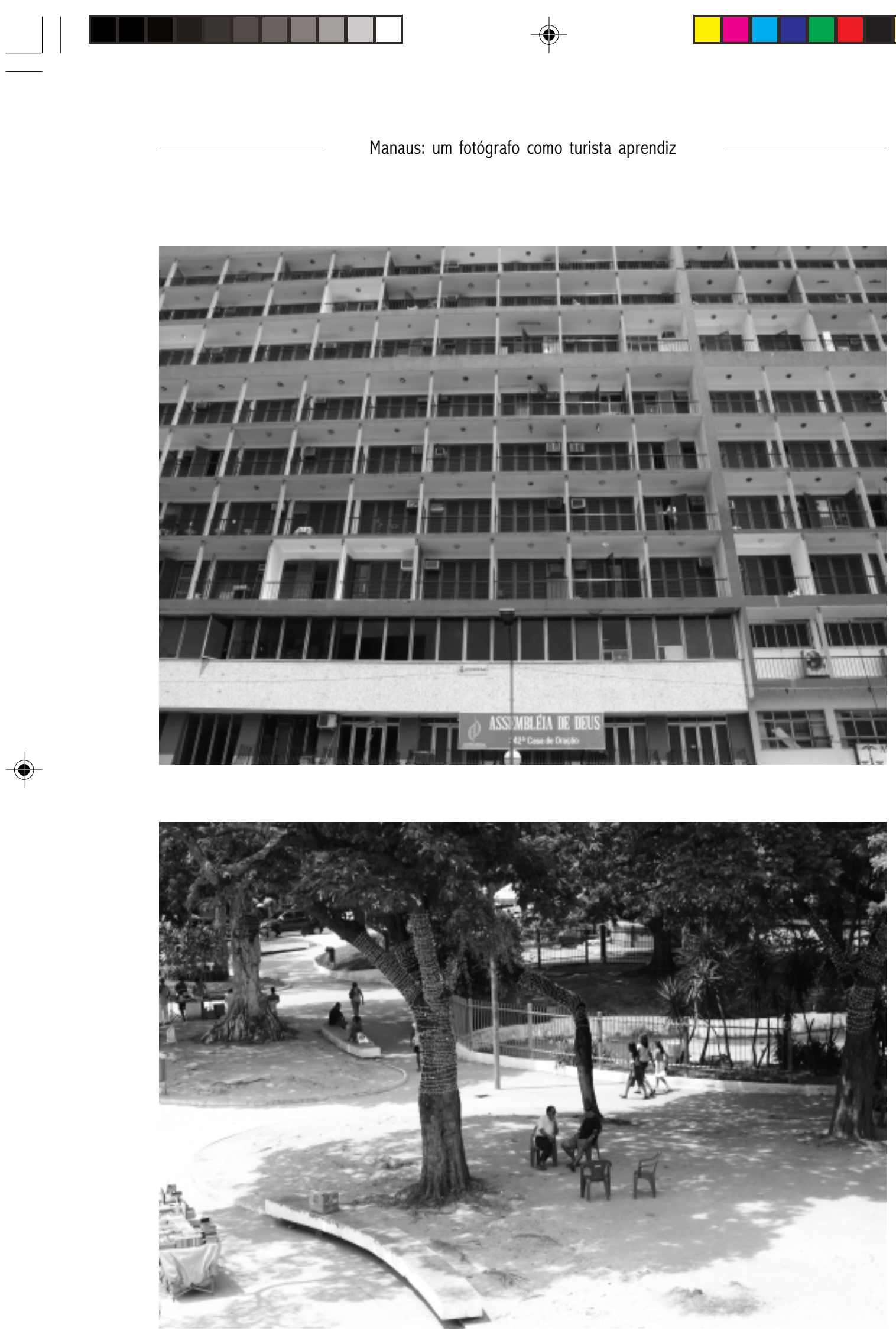


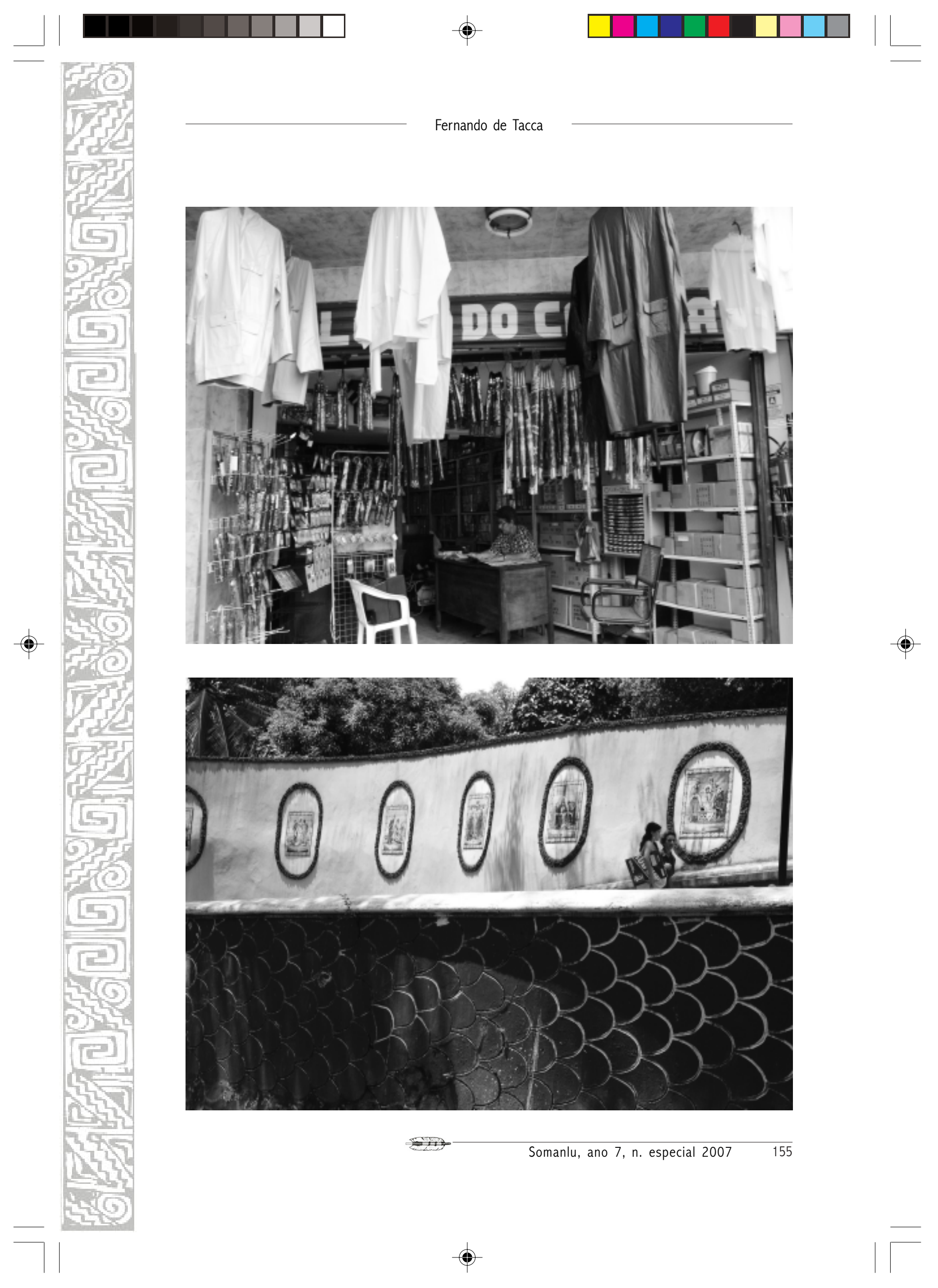




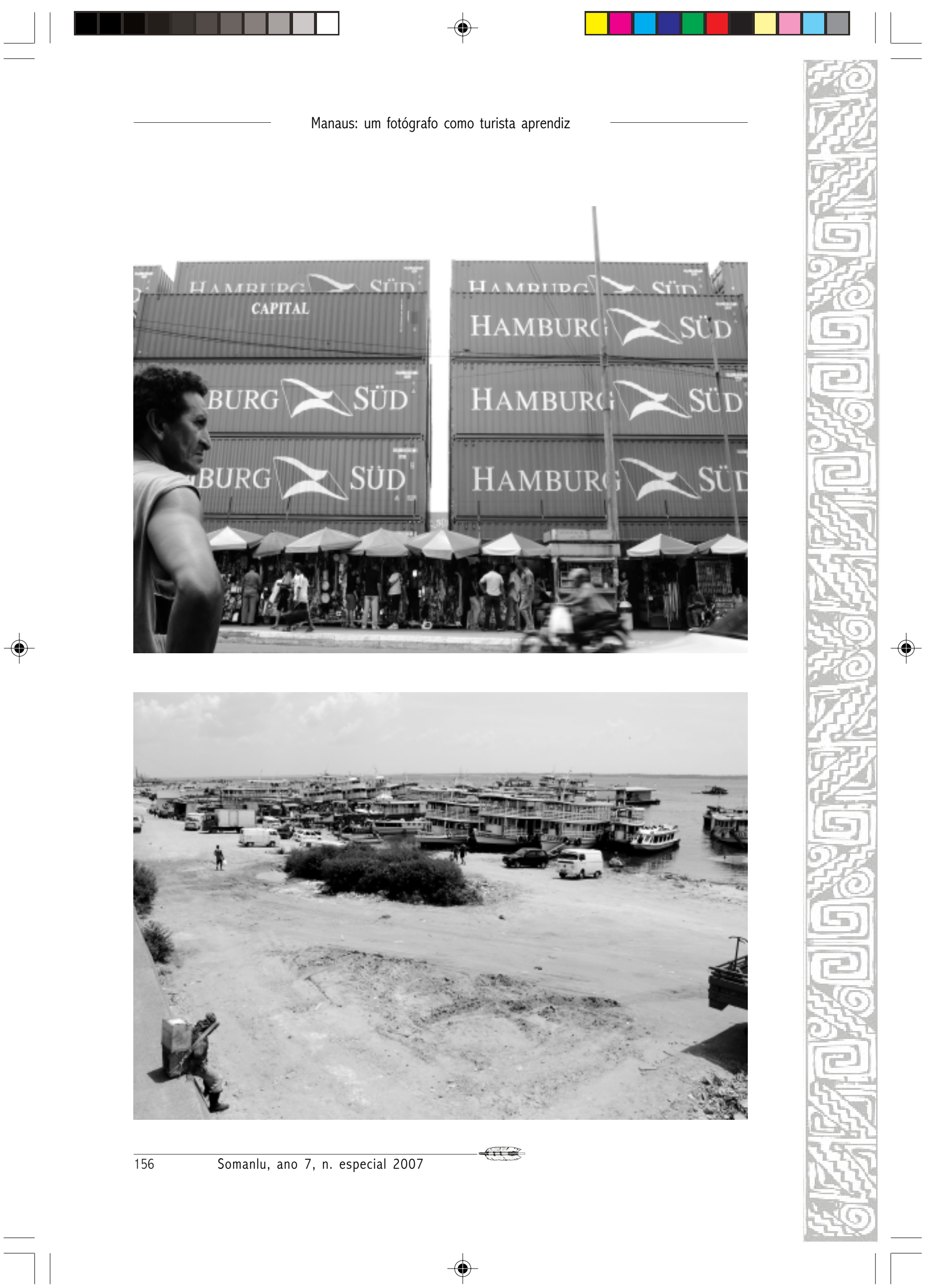




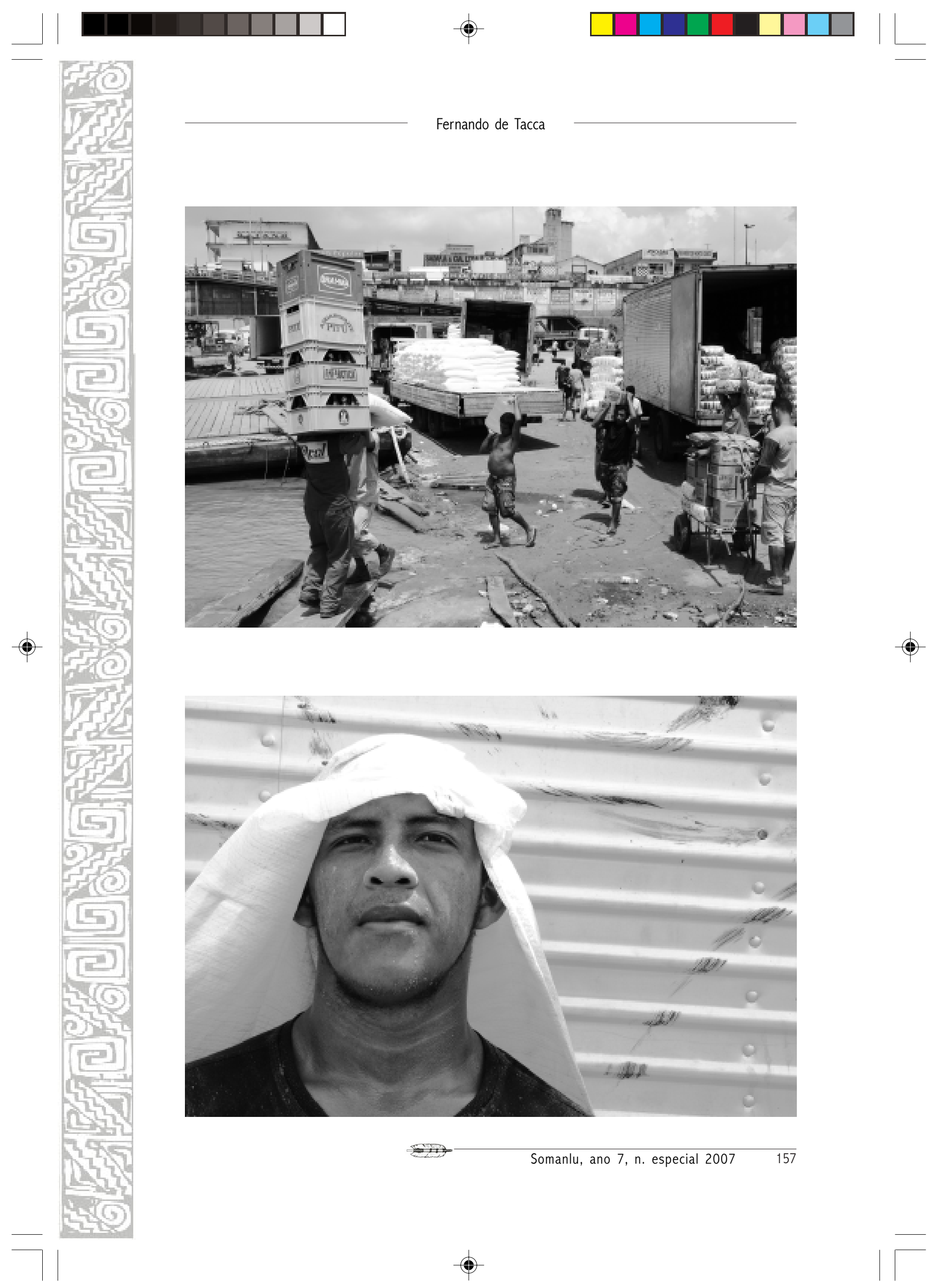




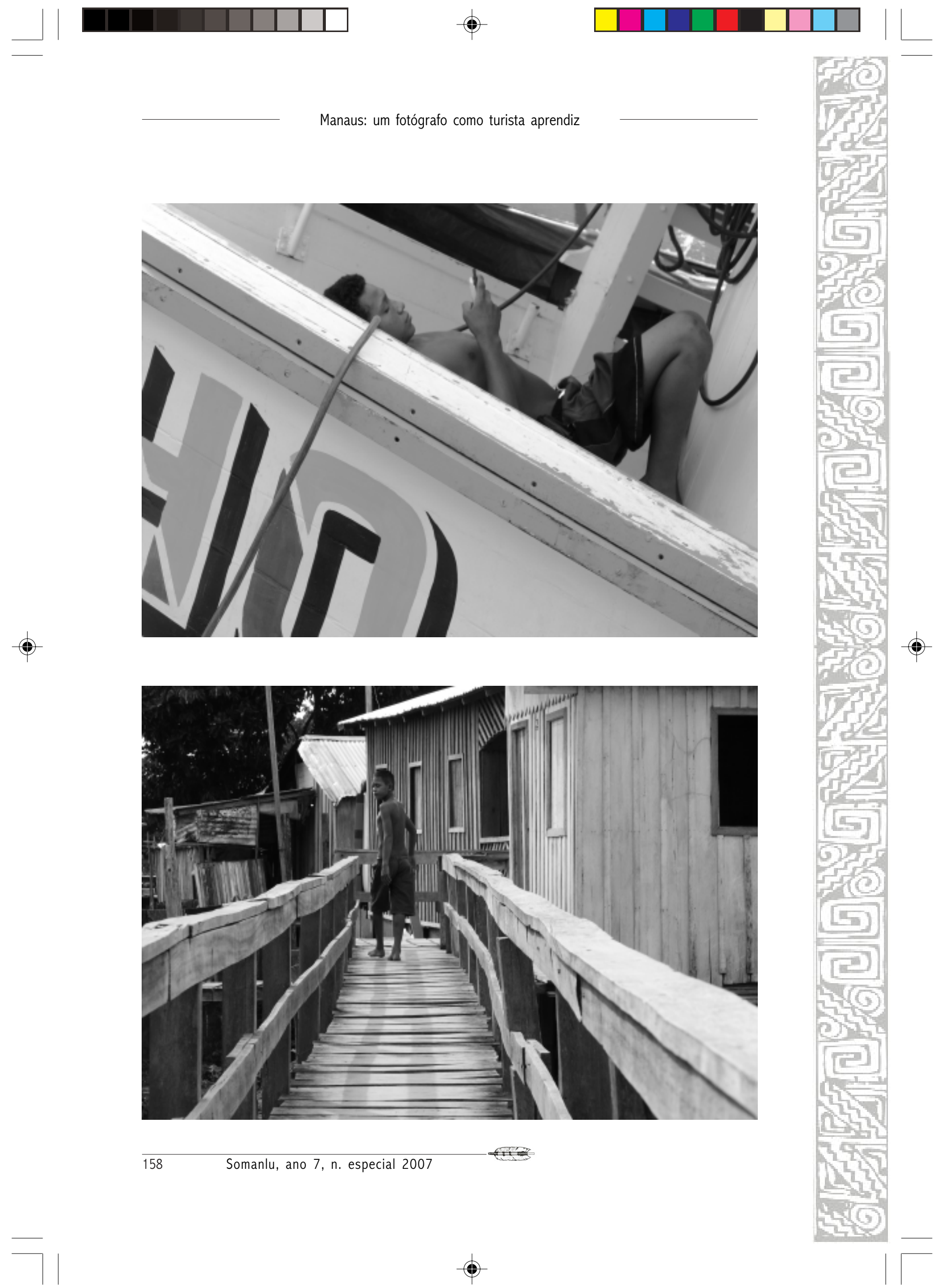




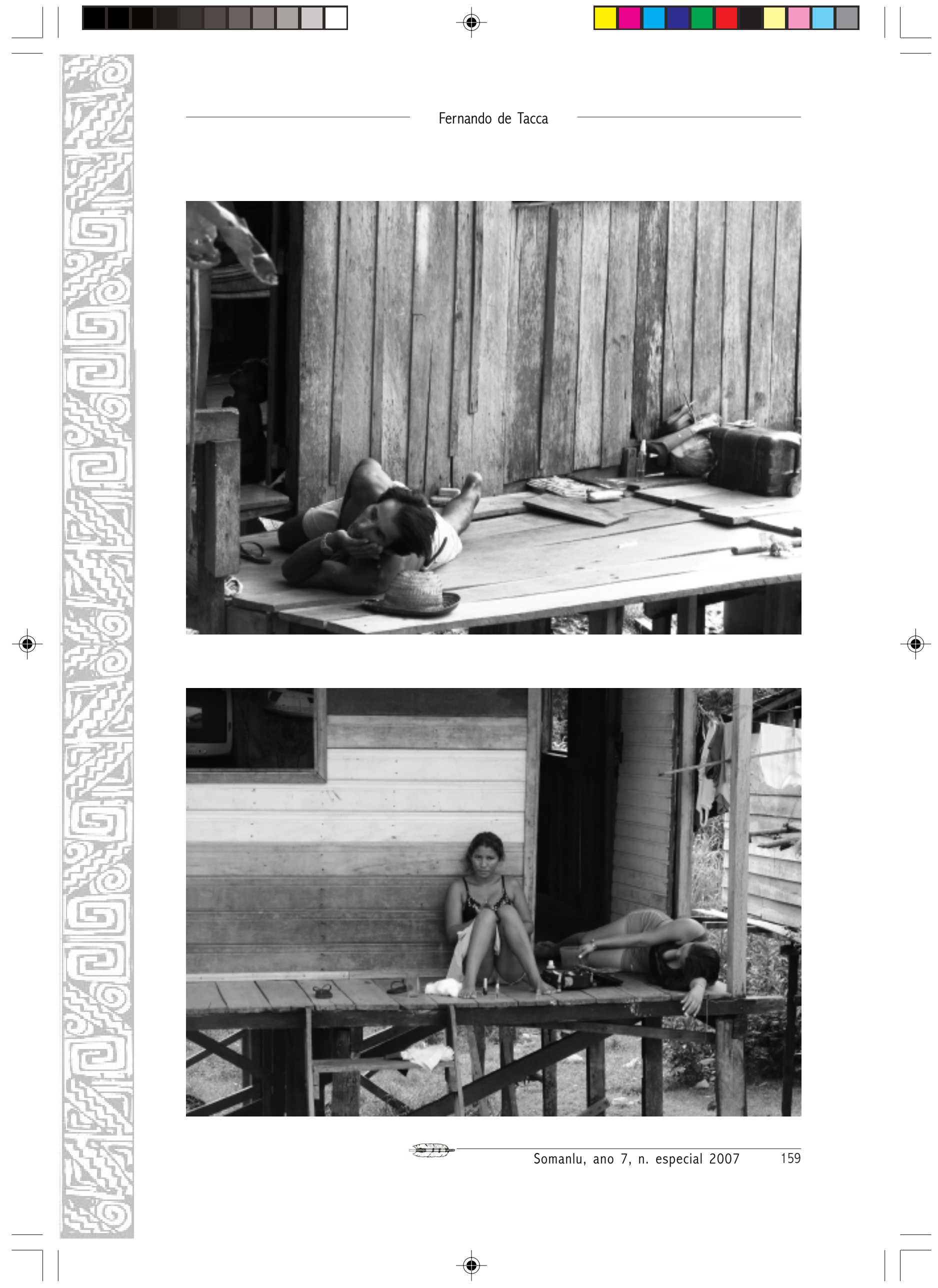




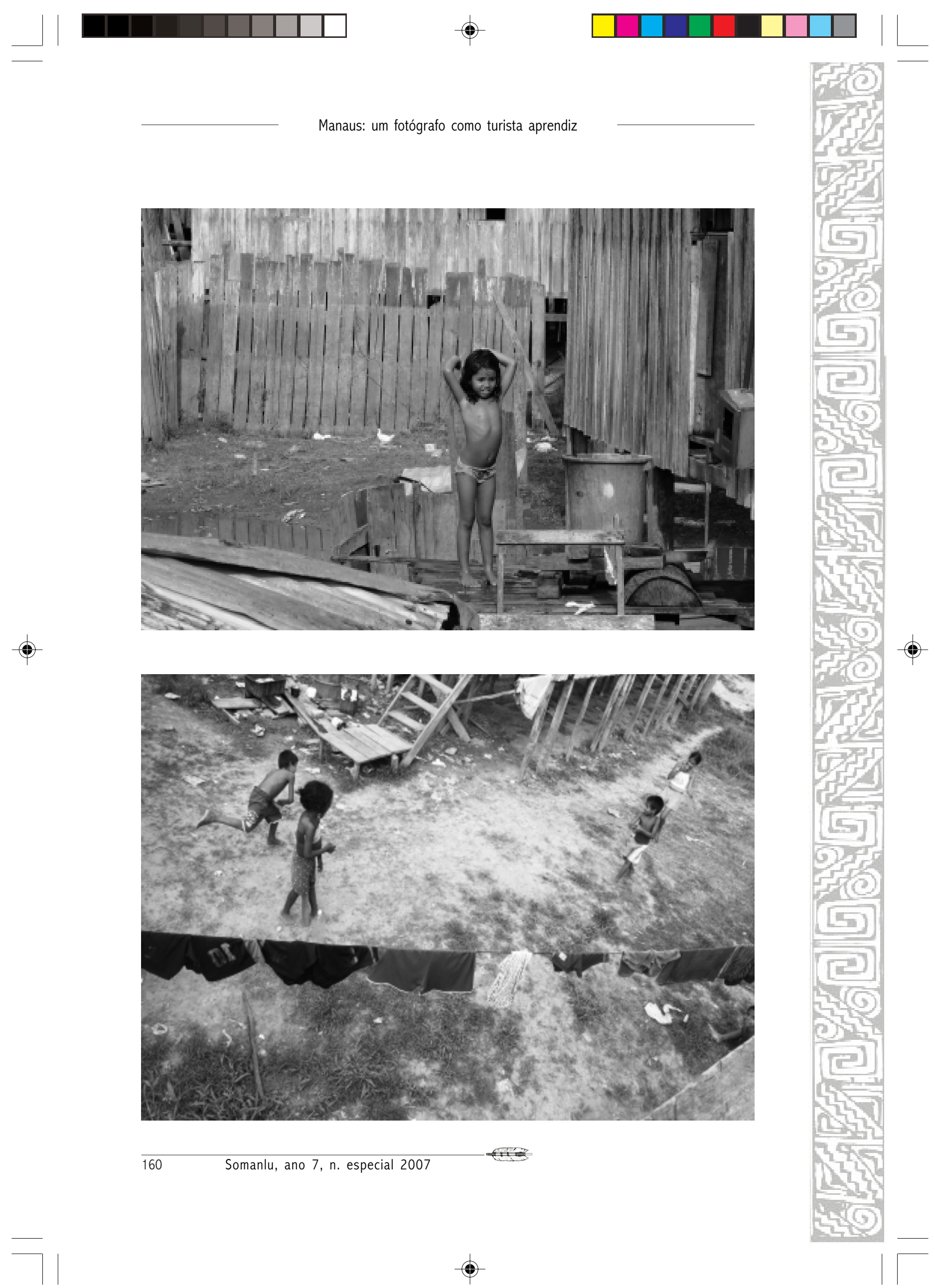

